\title{
A Comparison of Patient-Reported Outcome Measures Following Different Treatment Approaches for Adolescents with Severe Idiopathic Scoliosis: A Systematic Review
}

\author{
Josette Bettany-Saltikov ${ }^{1}$, Hans-Rudolf Weiss ${ }^{2}$, Nachiappan Chockalingam ${ }^{3}$, \\ Gokulakannan Kandasamy ${ }^{4}$, Tracey Arnell ${ }^{1}$ \\ ${ }^{1}$ School of Health and Social Care, University of Teesside, Middlesbrough, UK \\ ${ }^{2}$ Spinal Deformities Rehabilitation Services, Orthopaedic Practice, Gensingen, Germany \\ ${ }^{3}$ Faculty of Health Sciences, Staffordshire University, Stoke on Trent, UK \\ ${ }^{4}$ Sports and Exercise Section, School of Social Sciences Business and Law, Teesside University, Middlesbrough, UK
}

\begin{abstract}
Adolescent idiopathic scoliosis (AIS) is a three-dimensional deformity of the spine which is usually not symptomatic and which can progress during growth and cause a surface deformity. In adulthood, if the final spinal curvature surpasses a certain critical threshold, the risk of health problems and curve progression is increased. Although surgery is usually recommended for curvatures exceeding $40^{\circ}$ to $50^{\circ}$ to stop curvature progression, recent reviews have shed some light on the long-term complications of such surgery and to the lack of evidence for such complicated procedures within the scientific literature. Furthermore, a number of patients are very fearful of having surgery and refuse this option or live in countries where specialist scoliosis surgery is not available. Other patients may be unable to afford the cost of specialist scoliosis surgery. For these patients the only choice is an alternative non-surgical treatment option. To examine the impact of different management options in patients with severe AIS, with a focus on trunk balance, progression of scoliosis, cosmetic issues, quality of life, disability, psychological issues, back pain, and adverse effects, at both the shortterm (a few months) and the long-term (over 20 years). We searched CENTRAL, MEDLINE, EMBASE, CINHAL and two other databases up to January 2016 with no language limitations. We also checked the reference lists of relevant articles and conducted an extensive hand search of the grey literature. We searched for randomised controlled trials as well as prospective and retrospective controlled trials comparing spinal fusion surgery with no treatment or conservative treatment in AIS patients with a Cobb angle greater than $40^{\circ}$. We did not identify any evidence of superiority of effectiveness of operative compared to nonoperative interventions for patients with severe AIS. Within the present literature there is no clear evidence to suggest that a specific type of treatment is superior to other types of treatment.
\end{abstract}

Keywords: Adolescent; Exercise; Humans; Kyphosis; Scoliosis; Braces

Received Feb 18, 2016; Revised Mar 30, 2016; Accepted Apr 3, 2016

Corresponding author: Josette Bettany-Saltikov

School of Health and Social Care, University of Teesside, Borough Road, Middlesbrough, TS1 3BA, United Kingdom

Tel: +44-01642-342981, Fax: +44-01642-344124, E-mail: j.b.saltikov@tees.ac.uk 


\section{Introduction}

\section{Description of the condition}

Scoliosis is a complex three-dimensional deformity of the spine that comprises a lateral curvature in the frontal plane (this is a vertical plane that divides the body into front and back halves), thoracic lordosis in the sagittal plane (this is a vertical plane that divides the body into right and left halves) and transverse vertebral rotation, which is produced by rotation of the vertebrae in the transverse plane (horizontal plane); this results in the posterior elevation of the rib cage on the convex side of the curve and a depression on the concave side [1]. These underlying skeletal changes are usually reflected by a change in back shape, the unsightly shape of which is generally more of a concern to the patient than is the underlying skeletal deformity [2]. The condition if left untreated results in altered spinal mechanics and degenerative changes that lead to pain, loss of spinal mobility, and possible loss of function or disability. Cardiac and respiratory dysfunction may also accompany these symptoms, depending on the time of onset of the deformity [2]. These physical changes are accompanied by the psychological consequences resulting from the unsightly and deformed shape of the back: a restricted social life, a lower marriage rate, a higher divorce rate, fewer children per marriage, and increased psychiatric consultations, including eating disorders and increased suicide rate, have all been reported [3].

Whilst scoliosis can also occur secondary to certain diseases and conditions that affect the nervous and muscular systems of the body. The deformity can be caused by defects in spine formation at the embryo stage, or it can be part of certain syndromes. Very rarely, scoliosis can occur secondary to tumours. However, most cases of scoliosis ( $80 \%$ to $90 \%$ ) are called 'Idiopathic' because the underlying cause cannot be ascertained. Adolescent idiopathic scoliosis (AIS), which is the most common diagnosis, usually develops during adolescence- a period of rapid growth $[4,5]$.

According to the Scoliosis Research Society and the International Society on Scoliosis Orthopaedic Rehabilitation and Treatment [6], the prevalence of AIS is $2 \%$ to $3 \%$ in the general population. Almost $10 \%$ of patients with AIS will require some form of treatment, and up to $0.1 \%$ will eventually require surgery [7]. AIS is more commonly found in females (female/male ratio is around 7:1) and, except for extreme cases, AIS does not typically cause any health problems during growth; however, the resulting surface deformity frequently has a negative impact on adolescents that can give rise to quality of life issues and, in the worst cases, psychological disturbances [8].

The aetiology or causation of idiopathic scoliosis remains unclear [9-12]. Many theories on the causes of scoliosis have been proposed, such as the neuromuscular, growth and genetic theories [2]. This sums up all the hypotheses related to the cause of scoliosis as follows: "The normal spine in a growing person has a precise, precarious, delicate mechanical balance. Asymmetrical changes in primary structures, support structures, growth centres, the position of the spine and related neural or muscular components can all result in the development of scoliosis."

The potential for curve progression has been shown to be related to several factors, including the patient's gender, age, curve magnitude, bone maturity, rate of growth and growth potential at presentation. Dickson et al. [13] demonstrated that when curves of $10^{\circ} \mathrm{Cobb}$ and above were considered, the female-to-male ratio was 1.6:1. The Cobb angle is a method of measuring the angle of the spine that was devised by a surgeon named Cobb [7]. This value increased to $12: 1$ when curves greater than $20^{\circ}$ Cobb were considered. Female-to-male ratios for treatment were reported at 7:1 [14]. Moreover, when combining curves of all magnitudes, Lonstein and Carlson [15] found a negative correlation of age with the percentage incidence of progression. This means that the younger the child at presentation, the greater is the likelihood of progression. The same negative correlation is shown with the Risser sign. This measures how much mature bone has developed (ossification) in the upper rim of the pelvis (iliac crest). The greater the maturity of the child, the greater is the Risser sign. A low Risser sign indicates that greater potential for growth is left, and consequently the potential for curve progression is greater $[7,16]$. Curve magnitude, however, was found to have a positive correlation with the percentage incidence of progression. Thus, the greater the magnitude of the curve at presentation, the greater is the potential for progression.

Other factors taken into consideration when growth potential is determined are the changes in secondary sexual characteristics that take place during the growth spurt. Different results have been reported on the progression of various curve patterns. For example, Clarisse [17] and Fustier [18] reported that double curves progressed 
most in their studies, with an incidence of $67 \%$ and $75 \%$, respectively. Conversely, Bunnell [19] and Lonstein and Carlson [15] reported that thoracic curves were most progressive. All authors, however, demonstrated that lumbar curves progressed least. Other parameters of prognostic value include apical vertebral rotation $[20,21]$ and the rib vertebral angle [22]. When potential for curve progression is assessed, no single factor is taken in isolation, but all factors are taken into account in attempts to predict the likelihood for progression and make a treatment decision. Depending on the age of the individual at diagnosis, scoliosis evolves and may deteriorate rapidly during periods of fast growth spurt [23-25]. Whilst children grow until they have fully matured, growth is more rapid (growth spurt) during certain periods of childhood and adolescence [26].

Early diagnosis is difficult, especially in countries where scoliosis school screening is not implemented, as this condition is most often painless. External change to the body shape is minimal in the early stages and most changes in back shape occur predominantly on the back of the trunk, which makes it difficult for patients to see, and it can be concealed by their clothing [27]. Treatment of idiopathic scoliosis is determined by the deformity itself. As most patients with AIS progress during growth, the main aims of all interventions are to limit or stop the curvature progression, restore trunk balance $[23,24]$ and prevent the long-term consequences of the deformity.

\section{Description of the interventions}

Interventions for the prevention of AIS progression include scoliosis-specific exercises, bracing and surgery [28$31]$, and other interventions have been reported in the literature. The goals of all interventions are to correct the deformity and prevent further deterioration of the curve (i.e., prevent progression) and to restore trunk asymmetry and balance, while minimising morbidity and pain, allowing return to full function $[7,16]$.

Treatment approaches adopted by various orthopaedic surgeons and physicians specialising in the field of scoliosis around the world are divided, indicating lack of clinical equipoise across different professions and countries. In general, these approaches can be split grossly into two opposing groups. The first group consists of those who regard scoliosis-specific exercises as inefficient; members of the second group use these exercises and advocate their efficacy [30,32]. Similarly, bracing has been abandoned by some [33], but others support its use on the basis of existing weak evidence about efficacy [34]; fusion is generally considered to be necessary when AIS exceeds a certain degree (approximately $45^{\circ}$ to $50^{\circ}$ ), when previous treatments have failed or when AIS causes symptoms, but indications vary widely according to the preference of the treating physician/surgeon [33].

These two conflicting approaches to conservative management (nonsurgical vs. surgical approaches) seem to prevail in different regions of the world. In the United States, the United Kingdom, and Australia, the wait-andsee strategy prevails, but in various parts of continental Europe and Eastern and Southern Europe, conservative treatment (scoliosis-specific exercises and bracing) is considered beneficial for the patient and is used routinely by a large majority of scoliosis physicians and surgeons [29-31]. Scoliosis-specific exercises consist of individually adapted exercises that are taught to patients in a centre that is dedicated to scoliosis treatment. Patients learn an exercise protocol that is personalized according to their own medical and physiotherapeutic evaluation. On the other hand, usual generalised physiotherapy is more generic, consisting of low-impact stretching and strengthening activities like yoga, pilates or tai chi (taiji), but it can include many different exercise protocols. Whilst scoliosis-specific exercises are usually used for treating mild curves of less than $25^{\circ}$ to $30^{\circ}$, they are also used frequently with braces for curves over this threshold. No side-effects of exercise are known, except for muscle soreness that can be felt if the intensity of exercise is too great [31].

Bracing is defined as the application of external supports to the trunk; these are usually rigid and are applied with the aim of achieving maximum correction of the pathological curve [35]. Treatment commences when the curve is diagnosed as progressive, or when it exceeds a threshold of $30^{\circ}$ Cobb angle [7,30,31]. Braces generally need to be worn for a considerable period of time per day (at least 20 hours), the treatment extending over several years until the end of bone growth, which usually occurs at 16 years of age for girls and 18 years of age for boys [36]. This causes a significant negative impact on the lives of children and adolescents [37-39]. Other conservative management strategies can be found in the literature: shoe insoles, electrotherapy and chiropractic treatment have all been reported. However, to date, there is a dearth of evidence for the effectiveness of these forms of therapy. 
With regard to surgical interventions, a large multitude and variety are described in the literature [40]. These include different operative approaches (anterior, posterior, or combined) and many types of metal implants. The sophistication of spinal implants has grown rapidly in the past 10 to 15 years. Modern operative techniques follow principles of segmental spinal instrumentation (this means that each vertebra of the spine is attached to a metal rod, wires, or screws), and both anterior and posterior implants (operative rods, wires, or screws) are now available. Segmental instrumentation (with hooks or screws) can control sagittal and frontal plane correction in both lumbar and thoracic curves. In contrast to Harrington instrumentation, introduced in the 1960s [41], segmental instrumentation allows early mobilization of patients, thereby eliminating the need for postoperative casts and braces which were used in the past [1]. This type of surgery also reduces the risk of potential neurological complications due to distraction forces (these are forces applied to a body part to separate bony fragments or joint surfaces) that were applied with the Harrington instrumentation [41].

Countless studies have been published in the literature comparing different approaches to the spine (anterior, posterior or combined) and using various types of implants. A single threaded rod inserted through an anterior approach (from the front of the spine) was initially developed by Zielke, but this technique had a reported incidence of rod breakage as high as 31\% [42]. Further development of instrumentation resulted in the use of a double rod technique, such as Kaneda or Cotrel-Dubousset-Hopf, which prevented rod breakage but had the disadvantage of increasing the construct rigidity and favouring screw breakouts [43]. A further advantage was represented by a lower reoperation rate in double rod fixation $(0 \%)$ reported by Muschik et al. [44] as compared with single rod fixation (10\%) [42]. The anterior approach is desirable because it can reliably correct curvature yet save the vertebral levels instrumented in lumbar or thoracolumbar curves $[45,46]$. However, if appropriate consideration is not given to planning and fusing the correct segments (i.e., to neutral and stable vertebrae), this can lead to curve progression and disc degeneration postoperatively [47]. Unfortunately, with the anterior approach to surgery, there is a risk of potential trauma to the diaphragm and major abdominal organs. This type of surgery can also affect pulmonary function. If a patient has multiple curves, posterior fusion can achieve good correction and obviate the risks of anterior surgery [16]. The anterior approach also predisposes to a negative effect on pulmonary function for up to five years postoperatively [48]; therefore, some surgeons prefer a video-assisted thoracoscopy followed by posterior instrumentation, which allows them adequate spinal access but reduces the adverse effects on pulmonary function [49].

Luhmann et al. [50] suggested that instrumentation through a posterior approach (approaching surgery from the back of the spine) was as efficient as a combined anterior and posterior approach, but the former (posterior approach) eliminated the negative effect on pulmonary function. In other words, approaching the operative procedure from the back rather than from the front reduces the risks associated with deflating the lungs during the operative procedure [51]. A significant variety of implants and approaches to operative treatment of the spine are available, but double rod posterior instrumentation seems to have become the preferred operative intervention in cases where progression of scoliosis cannot be stopped by conservative treatment. All types of spinal fusion surgery are associated with significant risk both in the short term and in the long term. The short-term risk for spinal fusion surgery is estimated to be approximately $5 \%$, while long-term risks over a lifetime are estimated to exceed $50 \%$ [52], with reoperation rates ranging from $6 \%$ to $20 \%$ [24]. However, reoperation rates may be very high (up to $50 \%$ ) with the use of more recent instrumentation such as Cotrel-Debusset (CD) instrumentation [53].

\section{How the interventions might work}

Scoliosis-specific exercises can be used in three main clinical scenarios: (1) the sole use of exercise as the primary treatment of AIS for mild curves, (2) in conjunction with braces for moderate curves, and (3) during adulthood if the scoliosis curves exceed certain thresholds [54]. In the treatment of mild scoliosis, scoliosis-specific exercises can be used on curves greater than $10^{\circ}$ to $15^{\circ}$ but less than $25^{\circ}$ or $30^{\circ} \mathrm{Cobb}$. These intense three-dimensional spine and rib cage specific exercises are used to try to limit the progression of the curve and thereby avoid the use of a brace. This critical Cobb angle is generally regarded as the threshold for brace prescription $[7,55]$. In mild scoliosis cases for which exercise is prescribed, exercise is used predominantly according to the recommendations made by 
the Society on Scoliosis Orthopaedic and Rehabilitation Treatment (SOSORT)" [6]. The key objectives of physical exercise in mild cases of AIS include stabilisation of the spine combined with three-dimensional auto-correction of the pelvis, rib cage, and shoulders in combination with isometric muscle contractions $[54,55]$.

Whilst scoliosis-specific exercises use internal corrective forces (i.e., muscles), braces use external corrective forces to correct the trunk; this is usually achieved with the use of rigid supports. However, some braces (called soft braces) are made of material similar to elastic bands and comparable with materials used in physical therapy treatments $[35,56]$. The mechanical forces of the brace are used to straighten the spine and derotate the pelvis and shoulders to bring the whole body into normal alignment. Negrini et al. [57] state that the external and proprioceptive inputs due to bracing change the unnatural loading on the spine and rib cage, decrease asymmetrical movements and improve neuromuscular control; this facilitates proper spinal growth, neuromotor reorganization and changes in motor behaviours [34,58-65]. Although it has been reported in the literature that some braces can be uncomfortable to wear, especially for long periods, uncomfortable braces generally are a result of poor workmanship. Carefully crafted braces are however generally easily tolerated. Further, if bracing is not combined with scoliosis-specific exercises, weakening of the back muscles may occur.With regard to operative treatment of the scoliotic spine, the two main approaches discussed previously (anterior and posterior) aim to correct the spinal curvature (reduction of the Cobb angle) and fuse the spine with the help of bone grafts that allow the spine to heal to a solid and stable bone fusion mass (spinal fusion), supported by the instrumentation [66]. Posterior spinal fusion with instrumentation and bone grafting is performed through the patient's back while the patient lies on his or her stomach.

During scoliosis surgery, the surgeon attaches a metal rod onto the spinal curvature (one or both sides-this varies according on the type of instrumentation and procedure used) by using hooks or screws attached to the vertebral bodies [67]. Bony fusion of the spine is achieved by using bone graft usually taken from the patient (autograft) and/or artificial bone substitutes. This promotes bony ingrowth between the vertebrae and causes the spine to fuse and behave as a solid rod. The metal rods attached to the spine ensure that curve correction is maintained while bony spinal fusion occurs.

\section{Why it is important to do this review}

A literature search identified only three systematic reviews on this topic. The two reviews by Weis and Goodall and Weiss et al did not include full methodological appraisals of the quality of included studies $[68,69]$ and the third Cochrane review entitled 'Surgical versus nonsurgical interventions in people with AIS published in 2015 included only prospective studies with a control group and did not include any retrospective studies. A systematic review including all types of evidence with the inclusion of retrospective studies with a control group is urgently needed. From a patient and parent's perspective any spinal surgical intervention is often considered as a last option due to the fear and anxiety of having surgery. Additionally, numerous patients may have no choice but to either have no treatment or to have some form of nonsurgical intervention. This occurs primarily in patients living in developed countries who may not be able to afford the costs as well as for patients in developing countries where specialist scoliosis surgery is not available. It is very important for all patients and their parents who are considering surgery for severe curves in AIS, to know the short and long term outcomes of all treatment options (both surgical and nonsurgical). Being fully informed of all the short and long term outcomes as well as the complications and side effects for all current treatments approaches would significantly help service users and carers make fully informed decisions that are most suited to their child's specific scoliosis curve and quality of life.

The objective of this review was to evaluate and compare changes in trunk balance, progression of scoliosis, cosmetic issues, quality of life, disability, psychological issues and back pain, as well as adverse effects for severe curves $\left(>40^{\circ}\right)$ with both operative and nonoperative interventions provided in the short term (a few months) as well as in the long term (over 20 years).

\section{Materials and Methods}

\section{Criteria for considering studies for this review}

1) Types of studies

For the primary analysis we planned to combine the results of randomised control trials (RCTs) and quasirandomised control trials (QRCTs). We also planned to include both prospective and retrospective non- 
randomized studies (NRSs) with a control group because it was anticipated that very few RCTs would be found. We planned to include primary studies that compared operative interventions with non-operative interventions or no interventions (i.e., observation). We planned to exclude studies comparing non-operative methods alone (e.g., bracing vs. scoliosis-specific exercises) as two other Cochrane reviews cover these questions $[54,57]$.

\section{2) Types of participants}

We planned to include patients with AIS who were diagnosed and managed between 10 and 18 years of age, with a Cobb angle greater than $40^{\circ}$ (Scoliosis Research Society Guidance; accessed April 2015). We excluded any studies on participants with early-onset scoliosis (infant or juvenile) and scoliosis secondary to other conditions.

\section{3) Types of interventions}

We included all types of instrumented operative interventions with fusion aimed to provide curve correction and spine stabilisation. We excluded studies describing noninstrumented spinal correction and fusion because it has been shown that they do not provide any better outcome than is seen with untreated scoliosis [1]. We planned to compare instrumented operative interventions with different types of non-operative treatments, such as scoliosisspecific exercises, bracing, physiotherapy, chiropractic treatment, electrical stimulation and other non-operative interventions, as well as no treatment controls (i.e., observation).

\section{4) Types of outcome measures}

We examined outcomes (primary and secondary) measured in the immediate term (perioperative to 6 weeks postoperative), the short term (results at the end of bone growth), within 2 years, and over the long term (results in adulthood and in old age).

\section{5) Primary outcomes}

Change in trunk balance, measured in centimetres

- Frontal (coronal) balance (refers to the plane that divides the body into front and back halves);

- Lateral trunk shift; and

- Apical vertebral translation

Progression of scoliosis, measured by:

- Cobb angle in degrees (absolute values);

- Angle of trunk rotation in degrees (absolute values); and
- Number of participants who progressed by more than $5^{\circ} \mathrm{Cobb}\left(5^{\circ} \mathrm{Cobb}\right.$ is the standard clinical measure reported within various research papers and commonly used in clinical practice)

Cosmetic issues, as measured by:

- Validated scales or questionnaires: Walter Reed Visual Assessment Scale [70], Spinal Appearance Questionnaire [71], Trunk Appearance Perception Scale [72]; and

- Topographic measurements: the integrated shape imaging system (ISIS) or ISIS2 [73], Quantec [74], Formetric [75], measured in angles and millimetres

Quality of life

- Generic questionnaires: Short Form-36 (SF-36); and scoliosis-specific questionnaires: SRS-22 [76], Bad Sobernheim Stress Questionnaire [55], Brace Questionnaire [77]

Psychological issues

- Specific psychological questionnaires evaluating psychological concepts such as self-esteem, self-image etc., using specific questionnaires and subscales of SRS-22, BrQ, and SF-36

Back pain and disability

- Validated scales measuring pain intensity and pain duration, such as the visual analogue scale, McGill Pain Questionnaire and other validated specific questionnaires, as well as use of medication.

6) Secondary outcomes

Secondary outcomes comprised any adverse effects or complications reported in any included studies. These included blood loss, pseudarthrosis (a false joint where the bone has not healed adequately), deep wound infection, neurological complications, delayed Infections, pedicle screw misplacement, delayed paraparesis (weakness or partial paralysis in the lower limbs), loss of normal spinal function and decompensation (spinal imbalance) and increased spinal deformity, as well as death. We reported any adverse events in our review, even if they were not listed above.

\section{Search methods for identification of studies}

1) Electronic searches

We searched the following electronic databases since 1980. We did not search for papers before this date because a number of papers reporting the research on older instru- 
mentation might not have been relevant. Although clear advances in materials and design of spinal instrumentation have been made since 1980, the operative approach and training might still be the same even though materials have changed.

- CENTRAL (The Cochrane Library, January 2016)

- MEDLINE (1980 to January 2016)

- EMBASE (1980 to January 2016)

- CINAHL (1980 to January 2016)

- PsycINFO (1980 to January 2016)

- PEDro (1980 to January 2016)

The search strategy combined the study design filter for observational studies adapted from the Scottish Intercollegiate Guidelines Network with the usual Cochrane RCT filter, so that all study designs were captured by the search. The study design terms were combined with blocks of search terms for the disorder and the interventions. The strategy included subject headings (e.g., MeSH) and was adapted for the other databases (Appendices 1,2).

\section{2) Searching other resources}

The following strategies were also used.

- Screening the reference lists of all relevant papers.

- Searching the main electronic sources of ongoing trials (Cochrane Back Review Group Trials Register, National Research Register, meta-Register of Controlled Trials; Clinical Trials, World Health Organization International Clinical Trials Controlled Registry Platform).

- Searching the grey literature, including conference proceedings and $\mathrm{PhD}$ theses completed since 1980. For the latter, we searched the database, Dissertation Abstracts which lists American dissertations. This database also includes citations for dissertations from 50 British universities. To identify any further relevant British theses, we searched the Electronic Theses Online Service database (EThOS) provided by the British Library, which is an 'open access single point digital repository of UK research theses.'

- Contacting investigators and authors in this field for information on unpublished or incomplete trials.

All searches included non-English language literature.

3) Process of selection of research papers

We first developed a study selection form on the basis of the inclusion criteria. This was piloted and tested for both intra-observer and inter-observer reliability by two review authors, who then independently screened the search results by reading the titles and abstracts. Potentially relevant studies were obtained in full text, and once again they were independently assessed for inclusion by two review authors, who resolved any disagreement through discussion. A third review author was contacted if disagreements persisted. If a review author was also the author of a paper, another review author who had not authored any of the papers undertook the selection.

We did not select any papers before 1980 because research done on older instrumentation may not be relevant. Although clear advances in the materials and the design of spinal instrumentation have been made since 1980, the surgical approach and training may still be the same.

We did not find any relevant prospective RCTs, QRCTs, or NRSs with a control group. We found 10 retrospective studies, 9 of them could not be included because the patients in the comparative brace group had curves of less than $40^{\circ}$ at the beginning of treatment. Only one very recent study (abstract) by Ward et al. [78] met the full inclusion criteria. However as the full manuscript has not as yet been published we were unable to evaluate the methodological quality of the paper. As such, we were unable to carry out most of the pre-stated methodology.

4) Assessment of risk of bias in included studies

It was planned that the risk of bias for both randomised studies and NRSs would be assessed using the criteria recommended by the Cochrane Back Review Group [79,80], together with items from the Downs and Black [81] checklist, as outlined in Appendix 3. These criteria fall into five bias categories: selection bias, performance bias, attrition bias, detection bias and selective outcome reporting. The "assessment of risk of bias" form was piloted and tested for intra-observer and inter-observer reliability. It was planned that two review authors would independently assess the internal validity of the included studies. Any disagreement between the review authors was resolved by discussion; a third independent review author was consulted if disagreements persisted. We had also planned to blind the risk of bias assessment to trial authors, institution and journal and to score the risk of bias criteria as high, low or unclear and reported these ratings in the "risk of bias" table. We then rated the overall extent of risk of bias within each bias category (e.g., performance bias) as "Bias" or "No bias." 
Whilst it was difficult to provide an exhaustive list of all possible confounding variables at the start of the review, the review authors have experience in this field and were aware of most of the potential confounding variables that could occur when different treatment groups are compared. These may have included, for instance, demographic variables such as age, Risser sign (bone maturity), curve location and curve magnitude.

In regard to grading the quality of the evidence, we had planned to downgrade evidence from studies judged "no bias" for all five categories. Evidence would have been downgraded ( -1 point) when 3 or fewer categories for each study were judged to have bias. Evidence would have been downgraded by -2 points when four or more categories for each study were judged to have bias.

\section{5) Data extraction and management}

We performed the review following the recommendations of the Cochrane Handbook for Systematic Reviews of Interventions [80]. We had planned to do the following: to prepare a standardized data extraction form on the basis of all the inclusion criteria, which two authors would have piloted and tested for intra- and inter-observer reliability, and then used the form independently to extract data from the included papers; extracted raw data, including information about the study design (RCT, QRCT, prospective and retrospective controlled cohort study), study characteristics (country, recruitment modality, study funding, risk of bias) and participant characteristics (number of participants, age, sex, severity of scoliosis at baseline) as well as a description of experimental and comparison interventions, co-interventions, adverse effects, duration of follow-up, outcomes assessed and results, as well as any adverse effects. If a review author had been the author of a paper, another review author would have undertaken the data extraction process. Any disagreements were discussed with a third review author.

\section{6) Data synthesis}

The plan for the data synthesis was as follows: the results from clinically comparable trials would have been described qualitatively in the text. Regardless of whether sufficient data was available for the use of quantitative analyses to summarise the data, we would have assessed the overall quality of the evidence for each outcome. To accomplish this, we would have used the GRADE approach, as recommended in the Cochrane Handbook for Systematic Reviews of Interventions [80] and adapted in the updated Cochrane Back Review Group method guidelines [79]. Factors that would have decreased the quality of the evidence included the study design and risk of bias (all were retrospective studies and therefore all has a high risk of bias), inconsistency of results, indirectness (not generalisable), imprecision (sparse data) and other factors (e.g., reporting bias). The quality of the evidence for a specific outcome would have been reduced by a level, according to the performance of the studies against these five factors.

High-quality evidence: Consistent findings noted among at least $75 \%$ of RCTs with low risk of bias; consistent, direct and precise data and no known or suspected publication biases. Further research is unlikely to change the estimate or our confidence in the results.

Moderate-quality evidence: One of the domains not being met. Further research is likely to have an important impact on our confidence in the estimate of effect and may change the estimate.

Low-quality evidence: Two of the domains not being met. Further research is very likely to have an important impact on our confidence in the estimate of effect and is likely to change the estimate.

Very low-quality evidence: Three of the domains not met. We are very uncertain about the results. No evidence: No studies were identified that addressed this outcome.

\section{Results}

\section{Description of included studies}

Our search of databases identified 4798 records. After screening the records, we only found one paper by Ward et al. [78] that fully met our inclusion criteria (Fig. 1). We also found 9 articles that very closely met our criteria (Table 1) $[78,82-90]$. In these papers the initial Cobb angles in the surgically (over $40^{\circ} \mathrm{Cobb}$ ) and non-surgically (less than $40^{\circ}$ Cobb) treated groups at the initial hospital visit differed and the non-surgically treated (ST) group did not meet the criteria of having a scoliosis curve of $40^{\circ}$ or over at initial visit. In addition 6 of these papers were conducted on the same patient cohort with different outcomes reported within 6 different papers. All were retrospective cohort studies with a control group or retrospective case studies with a control group. There were no prospective studies with a control group. 


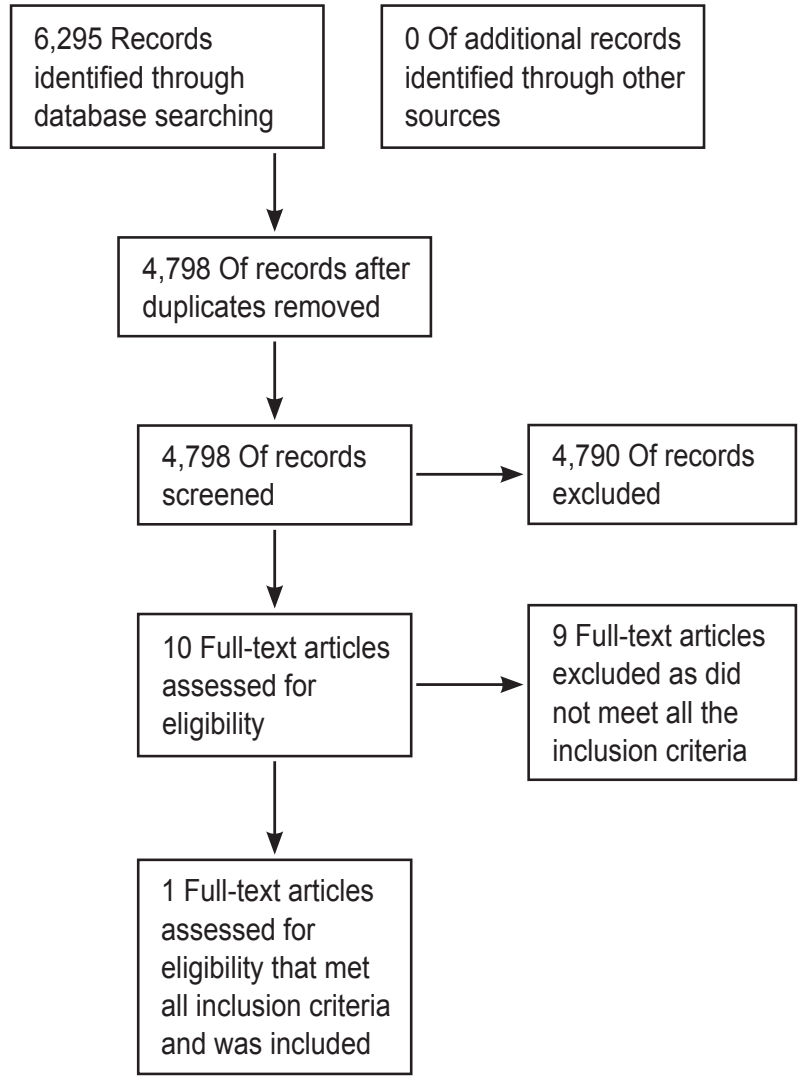

Fig. 1. Study flow diagram.

\section{Risk of bias}

All ten studies we found were retrospective studies with a control/comparison group and consequently this research design has a high risk of bias.

\section{Effects of interventions}

We only identified one retrospective study [78] with a comparison group that fully met our inclusion criteria but still for this study we couldn't appraise the full paper as we only had the abstract. Ward et al. [78] stated in his paper that "The similarity in SRS 22r scores between nonoperated and operated groups implies a limited benefit of surgery" for patients with AIS who had severe curves $\left(>40^{\circ}\right)$. Surgery is often recommended when curves exceed $40^{\circ}$. Since 2000 , Ward et al. [78] states that "surgical candidates have been counselled in a manner that did not bias them toward surgery." In this study the non-operative group of 141 AIS patient (with curves $>40^{\circ}$ ) was compared with patients $(n=197)$ who had surgical intervention. X-rays and SRS 22r scores were compared between the groups. Results: For the non-operative group the average age at follow up was $23.9 \pm 5.2$ years (range, $18-39$

Table 1. The 10 retrospective studies with a comparison group that we found were authored by references [78,82-90]

Ward TW, Roach JW, Friel N, Kenkre TS, Brooks MM. 22r Scores in non-operated AIS patients with curves over 40. In: Scoliosis Research Society 50th Annual Meeting and Course; Sep 30-0ct 3 2015; Minneapolis, MN, USA; Anniversary Abstract Booklet, Abstract 5, p.180-1 [78].

Simony A, Hansen EJ, Carreon LY, Christensen SB, Andersen MO. Health-related quality-of-life in adolescent idiopathic scoliosis patients 25 years after treatment. Scoliosis 2015;10:22 [82].

Andersen MO, Christensen SB, Thomsen K. Outcome at 10 years after treatment for adolescent idiopathic scoliosis. Spine (Phila Pa 1976) 2006;31:350-4 [83].

Danielsson AJ, Nachemson AL. Radiologic findings and curve progression 22 years after treatment for adolescent idiopathic scoliosis: comparison of brace and surgical treatment with matching control group of straight individuals. Spine (Phila Pa 1976) 2001;26:516-25 [84].

Danielsson AJ, Nachemson AL. Childbearing, curve progression, and sexual function in women 22 years after treatment for adolescent idiopathic scoliosis: a case-control study. Spine (Phila Pa 1976) 2001;26:1449-56 [85].

Danielsson AJ, Wiklund I, Pehrsson K, Nachemson AL. Health-related quality of life in patients with adolescent idiopathic scoliosis: a matched follow-up at least 20 years after treatment with brace or surgery. Eur Spine J 2001;10:278-88 [86].

Danielsson AJ, Nachemson AL. Back pain and function 22 years after brace treatment for adolescent idiopathic scoliosis: a case-control study-part I. Spine (Phila Pa 1976) 2003;28:2078-85 [87].

Danielsson AJ, Romberg K, Nachemson AL. Spinal range of motion, muscle endurance, and back pain and function at least 20 years after fusion or brace treatment for adolescent idiopathic scoliosis: a case-control study. Spine (Phila Pa 1976) 2006;31:275-83 [88].

Pehrsson K, Danielsson A, Nachemson A. Pulmonary function in adolescent idiopathic scoliosis: a 25 year follow up after surgery or start of brace treatment. Thorax 2001;56:388-93 [89].

Bunge EM, Juttmann RE, de Kleuver M, van Biezen FC, de Koning HJ. Health-related quality of life in patients with adolescent idiopathic scoliosis after treatment: short-term effects after brace or surgical treatment. Eur Spine J 2007;16:83-9 [90].

*Please note that papers [84-89] were conducted on the same population group but with different outcome measures reported in different papers. 
years), time since curve was $8.1 \pm 4.6$ years (range, $0.5-19$ years), and Cobb angle $50^{\circ} \pm 7^{\circ}$ (range, $\left.40^{\circ}-72^{\circ}\right)$. For 183 cases operated at an age $<18$ years the average preoperative Cobb angle was $60^{\circ} \pm 11^{\circ}$ versus $64^{\circ} \pm 14^{\circ}$ for 14 cases operated after age 18 . The non-operative group showed no statistical differences from the operative groups for Pain, Function, and Mental Health domains. Statistically signifi- cant improvement $(p<0.05)$ was found for total average SRS $22 \mathrm{r}$ score and self-image in the $<18$-yearold operated group and for satisfaction in both operated groups. However when published minimal clinically important difference values for selected SRS 22r domains are considered no comparison showed a conclusive clinical difference. So the improvements in SRS 22r scores for AIS patients following surgery are small and probably clinically insignificant. Alternative non-surgical approaches for AIS was recommended.

\section{Discussion}

\section{Summary of main results}

As stated above we only identified one retrospective study (abstract) with a comparison group that fully met our inclusion criteria. This study was presented by Ward et al. [78] at the latest SRS meeting in September 2015. Ward et al. [78] state in his paper that "the similarity in SRS $22 \mathrm{r}$ scores between non-operated and operated groups implies a limited benefit of surgery" for patients with AIS who had severe curves $\left(>40^{\circ}\right)$. We also identified nine retrospective studies with a comparison/control group that nearly met all our stated criteria with the exception that the braced group in these studies at initial treatment had a Cobb angle less than $40^{\circ}$ (see comment above).

\section{Overall completeness and applicability of evidence}

There is currently only one study non-randomized trialbased evidence from a retrospective study with a control group. As discussed above this review also found an additional 9 retrospective studies with a control group that nearly met the proposed inclusion criteria. Whilst we acknowledge that the nine retrospective studies found are considerably biased and the intervention groups within these studies had different initial Cobb angles, we believe that this review provides important information for patients and their families who are afraid of, refuse or cannot afford surgery when their curve reaches $40^{\circ}$ or above. We also believe that this review provides important information regarding research gaps in this field. The participants were patients with AIS who were diagnosed and managed between the ages of 10 and 18 years of age with severe curves of over $40^{\circ}$. Studies on participants with earlyonset scoliosis (infant or juvenile) or scoliosis secondary to other conditions were excluded.

Our literature search yielded no prospective randomized or non-randomised controlled studies comparing operative interventions to non-operative ones, which is consistent with previously published reviews on this topic $[68,69]$. The 9 retrospective studies with a control group [68,69,85-91] showed some differences between operative and non-operative groups in the short term, yet no significant differences were found in the long to very long term (20-25 years).

Retrospective studies are considered to have a much weaker research design leading to a much poorer quality research study. These studies are less expensive and are usually of much shorter duration (than prospective cohorts). They also require large sample sizes. Rare outcomes are difficult to study and there is much less control over subject selection and measurements. Crucially the risk for confounding variables and therefore error is also very high in this type of research design.

\section{Patient outcomes in the short-term (up to 1 year)}

1) Health Related Quality of Life outcomes

Bunge et al. [90] reported that short-term differences over approximately 10 months between Health Related Quality of Life outcomes (HRQoL) outcomes in surgically and non-ST AIS patients were negligible and could not support preference of one treatment above the other. This study was a cross-sectional analysis of the HRQoL of 109 patients with AIS who, after completing treatment, filled out the Dutch SRS-22 Patient Questionnaire. All patients had been treated either with a brace or surgery, or with a brace followed by surgery. Further scrutiny of the paper however revealed that ST patients had a better score in the "satisfaction with treatment" domain than BT patients; however, with modern braces this result may now be different. The recent developments of asymmetric high correction braces have a higher rate of success than the Boston brace [92-94]. Furthermore, it is important to consider that short-term results do not provide results for 
postoperative complications and side-effects, which may be revealed in the longer term. No other consistent differences in HRQoL were found between patients treated with a brace and patients treated surgically. Gender, curve type and curve size had no relevant effect on HRQoL.

\section{Patient outcomes in the mid-term (approximately less than 10 years after surgery or end of bracing)}

1) Activities of daily living and back pain

In a study of patient outcomes measured approximately 10 years after treatment for AIS, Andersen et al. [83] reported a generally high level of activities of daily living and found no significant differences between brace treated (BT) and ST patients. A total of 215 consecutive patients treated either by bracing or surgery received a questionnaire. The main topics of the questionnaire included patient demographics, back pain, activities of daily living. A total of 181 patients replied. The mean age at follow-up was 26.0 years. The level of back or leg pain was relatively low, though the BT patients had more pain than their ST peers. Compared with age-matched healthy controls, the SF-36 scores were lower in the AIS patients. Brace related questions revealed a significant impact of the disease and the treatment on the patients' lives. The patients also had moderately reduced perceived health status and activities of daily living, and increased pain with the ST patients generally at a better level than the BT.

In a very recent study Ward et al. [78] as described above, evaluated the SRS 22r Health related quality of life scores in non-operated AIS patients with curves of over $40^{\circ}$ and compared them to those of patients who had been operated. The authors found that "the similarity in SRS 22r scores between non-operated and operated groups" implies a limited benefit of surgery." Ward et al. [78] state that the natural history of scoliosis is relatively benign. However, surgery is often recommended when curves exceed $40^{\circ}$. Since 2000 , his surgical patients were counselled in a manner that did not bias them toward surgery. The non-operative group showed no statistical differences from the operative groups for Pain, Function, and Mental Health domains. Ward et al. [78] concluded that improvements in SRS 22r scores for AIS patients following surgery are small and probably clinically insignificant. The authors also suggested that alternative nonsurgical approaches for AIS should be considered.

\section{Patient outcomes in the longer term (approximately 20 years after surgery or end of bracing)}

The following 6 studies [82-88] reported on a number of different patient outcomes from what appear to be the same cohort of patients. These patients were treated between 1968 and 1977 and before the age of 21, either with distraction and fusion using Harrington rods or with a brace and who were followed for at least 20 years after completion of their treatment.

1) Health related quality of life 20 years after treatment Recently in 2015, Simony et al. [82] evaluated the longterm health related outcomes, in a cohort of AIS patients, treated 25 years ago. Method: Two hundred nineteen consecutive patients treated with Boston brace (Brace) or posterior spinal fusion (PSF) using Harrington-DDT instrumentation between 1983 and 1990 at Rigshospitalet Copenhagen, where patients were invited to participate in a long-term evaluation study. A validated Danish version of the Scoliosis Research Society 22R (SRS22R) and Short Form-36 (SF36v1) were administrated to the patients two weeks before the clinical and radiological examination. Results: 159 (72.6\%) patients participated in the clinical follow-up and questionnaires, 11 patients participated only in the questionnaires, 8 emigrated, 4 were excluded due to progressive neurological disease and 2 were deceased. The total follow-up was 170 patients (83\%), and the average follow up was 24.5 years (22-30 years). SRS22R domain scores were within the range described as normal for the general population with no statistical difference between the groups except in the satisfaction domain, where the PSF group had better scores than the braced group. The SF36 pain catastrophizing scale and mental health component scores in both AIS cohorts were similar to the scores for the general population. The authors concluded that HRQoLs, as measured by the SRS22R and SF-36, of adult AIS patients treated with Boston brace or PSF during adolescence were similar to the general population. No clinical progression of the deformity has been detected during the 25-year follow up period. The PSF group had a small but statistically significant higher score in the satisfaction domain compared to the braced group.

Danielsson et al. [86] also reported in 2001 on the health-related quality of life in patients with AIS at least 20 years after treatment with brace or surgery. Ninety- 
four percent of the ST patients and $91 \%$ of BT patients filled in a questionnaire comprising four different validated patient reported outcome measures (the SF-36, Psychological General Well-Being Index=, Oswestry Disability Back Pain Questionnaire, parts of SRS/MODEM'S questionnaire) as well as study-specific questions concerning the treatment, as part of an unbiased personal follow-up examination including radiography and clinical examination. An age and sex-matched control group of 100 participants without scoliosis was randomly selected and subjected to the same examinations. The results showed no differences in terms of socio-demographic data between the groups. Both ST and BT patients had slightly reduced physical function compared to the nonscoliosis controls. Neither of the mental health questionnaires showed any significant differences between the groups. A significantly greater number of the ST group (49\% of ST, $34 \%$ of BT and 15\% of controls) admitted limitation of social activities due to their back mostly due to difficulties with physical participation in activities or self-consciousness about appearance. Pain was a minor reason for limitation. No correlation was found between the outcome scores and curve size after treatment, curve type, total treatment time or age at completed treatment. Patients treated for AIS were found to have approximately the same HRQoL as the general population. A minority of the patients (4\%) had severely decreased psychological well-being, and a few (1.5\%) were severely physically disabled due to the back.

2) Radiological findings and curve progression 20 years or more after treatment

Danielsson and Nachemson [84] also reported on the radiological findings and curve progression 22 years after treatment, in which 252 patients attended a clinical and radiological follow-up assessment by an unbiased observer (91\% of the ST and $87 \%$ of the BT patients). This evaluation included chart reviews, validated questionnaires, clinical examination, and full- length standing frontal and lateral X-rays. The occurrence of any degenerative changes or other complications was noted. The deterioration of the curves was $3.5^{\circ}$ for all the ST curves and $7.9^{\circ}$ for all the brace-treated curves. Although the results were statistically significant, it should be highlighted that a difference of only $4^{\circ}$ in Cobb angle is reported between the two groups. This difference is well within the margin of error for Cobb angle measurement (the measurement error is reported to be $\left.5^{\circ}\right)$. Having said this, the overall complication rate after surgery was low: pseudarthrosis occurred in three patients, and flat back syndrome developed in four patients. Eight of the patients treated with fusion (5.1\%) had undergone some additional curve-related operative procedure. The lumbar lordosis was less in the ST than in the BT patients or the control group (mean, $33^{\circ}$ vs. $45^{\circ}$ and $44^{\circ}$, respectively). A decreased lumbar lordosis compared to normal lordosis can be indicative of back pain in future. Both ST and BT patients had more degenerative disc changes than the non-scoliosis control participants but no significant differences were found between the scoliosis groups.

3) Marital status, child bearing, number of children and low back pain over 20 years after treatment

Further Danielsson and Nachemson [87] reported that patients who had borne children and were sexually active appeared to function well with regard to marital status, number of children and low back pain. No statistically significant differences were found between the BT versus ST subjects. The limitations were largely because of the difficulties in participating in physical activities or self-consciousness about appearance. Pain was a minor reason for limitation. There was no correlation between progression of the major or lumbar curve and number of pregnancies, or between curve progression and age at first pregnancy. The scoliosis curve did not seem to increase as a result of childbearing and only minor problems occurred during pregnancy and delivery. Some patients, however, experienced a slight negative effect in their sexual life. The mean age for all the groups was 40 years. Of the ST and BT women, $85 \%$ were or had been married, as compared with $82 \%$ of the non-scoliosis control women. In the total cohort, 628 pregnancies had occurred. No significant mean difference existed between the groups in the number of children born (1.8 for the ST, 1.9 for the BT, and 2 for the control women). The age for the ST women (26.6 years) did not differ significantly from that for the BT women. There were no significant differences between the groups in rates for low back pain (35\% for the ST, $43 \%$ for the BT, and $28 \%$ for the control group) or for caesarean section (19\% for the ST, $14 \%$ for the BT, and $18 \%$ for the normal control group) during the first pregnancy. The rate of vacuum extractions was higher in the ST group (16\%) than in the control group (5\%) or the BT group (8\%). Limitation of sexual function from the back was admitted by $33 \%$ of 
the ST, $28 \%$ of the BT, and $15 \%$ of the control women.

4) Function and pain 20 years after treatment

Danielsson and Naachemson [87] also reported minimal pain and no dysfunction compared with normal controls 22 years after brace or operative treatment for AIS. Compared with ST patients, no significant differences were found except that BT patients experienced more affective components of their pain. Lumbar and thoracic back pain, although mild was significantly more frequent among the patients than the normal controls. Only $24 \%$ of the patients admitted daily pain and painkillers were sparsely used. The patients had a slightly, but significantly, worse back function as measured by the Oswestry disability index and general function score but general healthrelated quality of life was not affected. No differences could be seen in socio-demographic variables between the groups, except for having "ever been on sick leave because of the back." Furthermore, no differences could be found between patients with different curve types. No correlation could be found between pain and its localisation and curve size, an increase of at least $10^{\circ}$ since end of treatment, curve type, degenerative changes on any of the two lowest lumbar disc levels, body mass index, or smoking.

5) Spinal mobility and muscle endurance 20 years after treatment

For both BT and ST AIS patients, spinal mobility and muscle endurance were reduced more than 20 years after completed treatment [88]. Physical function was not severely restricted. For both ST and BT groups, lumbar spinal motion as well as muscle endurance was significantly decreased compared with healthy controls. For ST patients, better lumbar extensor and flexor muscle endurance or lumbar spinal mobility correlated with a better physical function. The length of fusion into the lumbar spine correlated inversely with lumbar range of motion, but the finger tip to floor distance was not affected (this is most probably because the patients may have overcompensated by increased flexion occurring at the hips rather than at the lumbar spine). BT patients with reduced lumbar spinal mobility experienced lumbar back pain more often than healthy controls.

6) Pulmonary function 20 years or more after treatment Finally patients treated by posterior fusion or a brace gradually increased their pulmonary function up to 25 years after treatment [89]. Smoking and curve size were not found to be risk factors for reduced pulmonary function and vital capacity (VC) increased from $67 \%$ immediately before surgery to $73 \%$ after surgery and to $84 \%$ at the long term follow up. In BT patients VC increased from $77 \%$ before treatment to $89 \%, 25$ years after start of the treatment. The mean Cobb angles at the follow up study were $40^{\circ}$ in both ST and BT patients. The authors stated that these results of lung volumes did not correlate with pre-treatment or post-treatment Cobb angles or smoking habits.

\section{Evidence from other AIS studies in the literature}

As stated previously, complications can include any adverse effects such as blood loss, pseud-arthrosis (a false joint where the bone has not healed adequately), deep wound infection, neurological complications, delayed Infections, pedicle screw misplacement, delayed paraparesis (weakness or partial paralysis in the lower limbs), loss of normal spinal function and decompensation (spinal imbalance) and increased spinal deformity.

The recent study on the long-term effects of CD dorsal double rod instrumentation [53] where long-term risks over a lifetime were very high and thought to exceed 50\% [68] must be viewed with caution. Furthermore many issues (e.g., metallosis) may not as yet have been investigated, and later in life and into old age various problems could occur, which may not necessarily be attributed to spinal fusion surgery [95]. In a recent article, the problem of "metallosis" has been described. This is described as the deposition and build-up of metal debris in the soft tissues of the body. The consequences of the findings of "metallosis" are not yet clear [91]. It is for these reasons that a dialogue is essential and must be in keeping with the goal that treatments should always incur the least potential harm and maximum potential benefit in both the short and long term [96] Indeed the findings of a relatively recent study published in 2011 put forward by Westrick and Ward [97] support our findings and also reported that "no long-term, prospective controlled studies exist to support the hypothesis that operative intervention for AIS is superior to non-operative interventions or natural history." Whilst surgery does reliably arrest the progression of deformity, achieves permanent correction in the frontal plane Cobb angle, and improves appearance, there is no medical organic necessity for surgery based on the current 
body of literature.

Furthermore research from Weinstein et al.'s [98] seminal work in 2003, in what is perhaps the field's best known study on the natural history of untreated adults with scoliosis, found that patients with "late onset AIS (LIS) are still productive and functional to a high level at a 50-year follow-up." Indeed Weinstein states in his paper that "untreated LIS causes little physical impairment other than back pain and cosmetic concerns." With regards to the current effectiveness of non-operative interventions, two recent Cochrane reviews, one on the effectiveness of Braces [57] on AIS and the other on the effectiveness of scoliosis-specific exercises [54] on AIS have both reported low to very low quality evidence for their effectiveness. Further 2 very recent RCT's reported by Weinstein [99] and Monticone et al. [100] have shown that both Braces and Physiotherapy based scoliosis-specific exercises were significantly effective in treating AIS patients with mild and moderate curves.

Weinstein [99] found that bracing significantly decreased the progression of high-risk curves to the threshold for surgery in patients with AIS and that the benefit increased with longer hours of brace wear. Monticone et al. [100] and many others [101-105] reported that an RCT of scoliosis-specific exercises including active self-correction and task-oriented exercises reduce spinal deformity and improve quality of life in subjects with mild AIS. The programme of active self-correction and task-oriented exercises was superior to traditional non scoliosis-specific exercises in reducing spinal deformities and enhancing the HRQoL in patients with mild AIS. The effects lasted for at least 1 year after the intervention ended.

In the field of AIS most physicians, surgeons, physical therapists and other allied health professionals would agree that there are still many unknowns. Few 'ideal' treatment protocols exist for the patients suffering from scoliosis, especially from the perspective of the adolescent patient and his/her parents. Moramarco [96] suggests that full disclosure about the potential unknowns of surgery in the short and long term should be mandatory so families may weigh the myriad of unknowns against the perceived benefits of surgery and enable them to make fully informed decisions based on current evidence together with the Health care professional, that is best for their daughter or son.

As stated previously all types of spinal fusion surgery are associated with significant risk both in the short term and in the long term. The short-term risk for spinal fusion surgery is estimated to be approximately $5 \%$, while longterm risks over a lifetime are estimated to exceed 50\% [68], with re-operation rates ranging from $6 \%$ to $20 \%$ [76]. However, re-operation rates may be very high (up to $50 \%$ ) with the use of more recent instrumentation such as $\mathrm{CD}$ instrumentation [53].

Considering the above, it would be reasonable to argue that, non-operative interventions and/or other exercise intervention protocols should be considered first when the curve is still small and surgery should only be considered when non-operative interventions have been shown not to work. In addition, clinicians should also provide full disclosure of the lack of long term scientific evidence for surgery and the possible long-term consequences and complications that may arise, to the patients and their relatives. This also raises an awareness of lack of scientific developments in patient-specific interventions within the clinical management of scoliosis. There is a clear need for inter-professional working between surgeons, orthotists, physical therapists and other health care professionals to develop new and effective clinical management procedures that benefits the patient and improves the socioeconomic impact.

In summary we can conclude that there is only 1 retrospective controlled abstract was available for comparing operative to non-operative interventions where their results concludes that there is no difference between surgical and non-surgical management of AIS patients. Also consideration should be given to the fact that current and recent evidence by Mueller and Gluch [53] suggests that the re-operation rate for some types of instrumentation currently used in clinical practice is low in the very short term but may be as high as $50 \%$ in the long-term and over a life-time.

\section{Implications for Practice}

\section{Adolescents with idiopathic scoliosis and their parents/ care-givers and relatives}

There is a clear lack of evidence for both the short and long term effectiveness of operative over non-operative management. Considering the fact that surgery is a huge decision both for young teenagers as well as their parents, the lack of both short and long term outcomes in this area prevents service users from making decisions on treat- 
ment based on high quality evidence. Those interested may wish to promote high quality studies in this area.

\section{Clinicians}

Despite thousands of studies currently available in the area of the operative effectiveness on AIS nothing is as yet available comparing the 2 main methods of treatment. It would appear that clinicians have no choice but to continue with their current practices using clinical judgement because of the lack of both randomised as well as prospective controlled evidence to help guide their choice of intervention. Clinicians have the responsibility to promote as well as help support and conduct high quality research in this area.

\section{Policy makers}

Policy makers today have randomised evidence for bracing and scoliosis-specific exercises only, upon which to base guidelines for the management of adolescents with idiopathic scoliosis. They are likely to continue to rely on opinion and clinical experience when making their recommendations.

\section{Commissioners of services}

Until such time that high quality evidence is made available both for the short term as well as the long term effectiveness of operative versus non-operative treatment it is important that commissioners also consider commissioning alternative non-operative interventions such as bracing and physiotherapy based scoliosis-specific exercises for smaller curves [6]. Commissioners should also consider re-introducing school screening for adolescents with scoliosis as currently in many countries due to the abolition of scoliosis school screening programs, most patients with small curves for whom non-operative management is most appropriate are being missed. Frequently the curve is diagnosed only when the child 's curve has progressed significantly and is over $45^{\circ}$ or $50^{\circ}$ at which point the only treatment option is surgery.

\section{Implications for research}

Clinically meaningful comparative studies or prospective studies with a control group are urgently needed to help guide clinicians in their management of adolescents with idiopathic scoliosis. Available retrospective publications suggest that such studies might be able to be conducted prospectively on a patient preference basis. However it might be very difficult to obtain ethical approval for such a study. The authors of this review are aware that due to the long-term nature of these studies significant funding may be required. Funders of studies may wish to make this important group of people a priority for future research. This review has also highlighted the urgent need for prospective studies with a control group to be conducted. A patient-preference prospective comparative study of operative intervention vs. high quality conservative treatment as available today in specialist conservative centre is urgently needed for curves over $40^{\circ}$. This prospective study could be based on the patients' decision for either treatment approach; after a full disclosure based on the evidence in the literature, of not only the potential gains that could be achieved with operative treatment but also to include a full disclosure of the high rate of long-term complications. Researchers should also explore the full use of biomechanical computer simulations and patient specific modelling to inform and assess any clinical management procedures. This could be made possible with the advances in technology and computer applications.

\section{Conclusions}

In conclusion further primary studies are urgently needed to evaluate the effectiveness as well as the short and long term impact of operative versus non-operative interventions on patient-centred outcomes. Their quality of life and disability, psychological issues such as back pain and disability change in trunk balance and progression of scoliosis, cosmetic issues in the mid to long term (old age) as well as the adverse effects of both types of interventions both in the short term to the mid-term (adulthood) as well in as in the long term to old age (70-80 years old). We are well aware that the design of such a prospective study with a comparative non-operative intervention would need significant planning and funding. Nevertheless we believe that a well conducted multicentre study that might include the use of a world-wide registry (many of which are already on-going) might make this possible. 


\section{Conflict of Interest}

HRW is receiving financial support for attending symposia and receives royalties from Koob GmbH \& Co KG. The company is held by the spouse of HRW.

None of the other authors report any competing interest or potential conflict of interest.

\section{Acknowledgments}

This extended comprehensive review is based on a Cochrane protocol published in 2013 (Bettany-Saltikov J, et al. Cochrane Database Syst Rev 2013;(7):CD010663) and a Cochrane review published in 2015 (Bettany-Saltikov J, et al. Cochrane Database Syst Rev 2015;(4):CD010663). In the protocol of the former article, the authors have provided the following background information which is still valid today and was updated according to actual literature. The latter article included prospective and randomized studies, only. Purpose of this review was (1) to update the literature search and (2) to also include retrospective controlled papers so as to allow to draw a more comprehensive figure of the literature there currently is on that topic.

\section{References}

1. Lonstein JE, Winter RB, Bradford DS, Ogilvie JW. Moe's textbook of scoliosis and other spinal deformities. Philadelphia: Saunders; 1987.

2. White AA, Panjabi MM. Clinical biomechanics of the spine. 2nd ed. Functional analysis and clinical applications. Baltimore: Lippincott Williams and Wilkins; 1990.

3. Freidel K, Petermann F, Reichel D, Steiner A, Warschburger P, Weiss HR. Quality of life in women with idiopathic scoliosis. Spine (Phila Pa 1976) 2002; 27:E87-91.

4. Kanayama M, Tadano S, Kaneda K, Ukai T, Abumi K. A mathematical expression of three-dimensional configuration of the scoliotic spine. J Biomech Eng 1996;118:247-52.

5. Stokes IA, Spence H, Aronsson DD, Kilmer N. Mechanical modulation of vertebral body growth. Implications for scoliosis progression. Spine (Phila Pa 1976) 1996;21:1162-7.

6. Negrini S, Aulisa AG, Aulisa L, et al. 2011 SOSORT guidelines: orthopaedic and rehabilitation treatment of idiopathic scoliosis during growth. Scoliosis 2012; 7:3.

7. Lonstein JE. Scoliosis: surgical versus nonsurgical treatment. Clin Orthop Relat Res 2006;443:284-59.

8. Reichel D, Schanz J. Developmental psychological aspects of scoliosis treatment. Pediatr Rehabil 2003; 6:221-5.

9. Sevastik B, Xiong B, Sevastik J, Lindgren U, Willers U. Rib-vertebral angle asymmetry in idiopathic, neuromuscular and experimentally induced scoliosis. Eur Spine J 1997;6:84-8.

10. Stokes IA. Analysis of symmetry of vertebral body loading consequent to lateral spinal curvature. Spine (Phila Pa 1976) 1997;22:2495-503.

11. Machida M. Cause of idiopathic scoliosis. Spine (Phila Pa 1976) 1999;24:2576-83.

12. Burwell RG, Dangerfield PH. Adolescent idiopathic scoliosis: hypothesis of causation. In: Burwell RG, Dangerfield PH, Lowe TG, Margulies JY, editors. Etiology of adolescent idiopathic scoliosis: current trends and relevance to new treatment approaches. Vol. 14. State of the art review: spine. Philadelphia: Hanley \&Belfus Inc.; 2000. p.319-33.

13. Dickson RA, Lawton JO, Archer IA, Butt WP. The pathogenesis of idiopathic scoliosis. Biplanar spinal asymmetry. J Bone Joint Surg Br 1984;66:8-15.

14. Rogala EJ, Drummond DS, Gurr J. Scoliosis: incidence and natural history: a prospective epidemiological study. J Bone Joint Surg Am 1978;60:173-6.

15. Lonstein JE, Carlson JM. The prediction of curve progression in untreated idiopathic scoliosis during growth. J Bone Joint Surg Am 1984;66:1061-71.

16. Bridwell KH. Surgical treatment of idiopathic adolescent scoliosis. Spine (Phila Pa 1976) 1999;24:2607-16.

17. Clarisse P. Prognostic evolution of minor scoliosis curves of 10 degree to 29 degrees during the growth spurt [thesis]. Lyon: Claude Bernard University; 1974.

18. Fustier J. Spontaneous evolution of idiopathic scoliosis under 45 degrees during growth: retrospective study from the Lyon centre of rehabilitation [thesis]. Lyon: Claude Bernard University; 1980.

19. Bunnell WP. The natural history of idiopathic scoliosis before skeletal maturity. Spine (Phila Pa 1976) 1986;11:773-6.

20. Weinstein SL, Ponseti IV. Curve progression in idiopathic scoliosis. J Bone Joint Surg Am 1983;65:447- 
55.

21. Perdriolle R, Vidal J. Thoracic idiopathic scoliosis curve evolution and prognosis. Spine (Phila Pa 1976) 1985;10:785-91.

22. Mehta MH. The rib-vertebra angle in the early diagnosis between resolving and progressive infantile scoliosis. J Bone Joint Surg Br 1972;54:230-43.

23. Goldberg CJ, Moore DP, Fogarty EE, Dowling FE. The natural history of early onset scoliosis. Stud Health Technol Inform 2002;91:68-70.

24. Asher MA, Burton DC. Adolescent idiopathic scoliosis: natural history and long term treatment effects. Scoliosis 2006;1:2.

25. Hawes MC, O'Brien J P. The transformation of spinal curvature into spinal deformity: pathological processes and implications for treatment. Scoliosis 2006; $1: 3$.

26. Weiss HR. Physical therapy intervention studies on idiopathic scoliosis: review with the focus on inclusion criterial. Scoliosis 2012;7:4.

27. Roaf R. Spinal deformities. 2nd ed. Tunbridge Wells: Pitman Medical; 1980.

28. Rowe DE, Bernstein SM, Riddick MF, Adler F, Emans JB, Gardner-Bonneau D. A meta-analysis of the efficacy of non-operative treatments for idiopathic scoliosis. J Bone Joint Surg Am 1997;79:664-74.

29. Lenssinck ML, Frijlink AC, Berger MY, Bierman-Zeinstra SM, Verkerk K, Verhagen AP. Effect of bracing and other conservative interventions in the treatment of idiopathic scoliosis in adolescents: a systematic review of clinical trials. Phys Ther 2005;85:1329-39.

30. Negrini S, Aulisa L, Ferraro C, et al. Italian guidelines on rehabilitation treatment of adolescents with scoliosis or other spinal deformities. Eura Medicophys 2005;41:183-201.

31. Weiss HR, Negrini S, Hawes MC, et al. Physical exercises in the treatment of idiopathic scoliosis at risk of brace treatment: SOSORT consensus paper 2005. Scoliosis 2006;1:6.

32. Weiss HR, Negrini S, Rigo M, et al. Indications for conservative management of scoliosis (guidelines). Scoliosis 2006;1:5.

33. Dolan LA, Weinstein SL. Surgical rates after observation and bracing for adolescent idiopathic scoliosis: an evidence-based review. Spine (Phila Pa 1976) 2007; 32:S91-S100.

34. Negrini S, Marchini G. Efficacy of the symmetric, patient-oriented, rigid, three-dimensional, active (SPoRT) concept of bracing for scoliosis: a prospective study of the Sforzesco versus Lyon brace. Eura Medicophys 2007;43:171-81.

35. Rigo M, Negrini S, Weiss HR, Grivas TB, Maruyama T, Kotwicki T. 'SOSORT consensus paper on brace action: TLSO biomechanics of correction (investigating the rationale for force vector selection)'. Scoliosis 2006;1:11.

36. Katz DE, Durrani AA. Factors that influence outcome in bracing large curves in patients with adolescent idiopathic scoliosis. Spine (Phila Pa 1976) 2001; 26:2354-61.

37. Fallstrom K, Cochran T, Nachemson A. Long-term effects on personality development in patients with adolescent idiopathic scoliosis. Influence of type of treatment. Spine (Phila Pa 1976) 1986;11:756-8.

38. Noonan KJ, Dolan LA, Jacobson WC, Weinstein SL. Long-term psychosocial characteristics of patients treated for idiopathic scoliosis. J Pediatr Orthop 1997;17:712-7.

39. Climent JM, Sanchez J. Impact of the type of brace on the quality of life of adolescents with spine deformities. Spine (Phila Pa 1976) 1999;24:1903-8.

40. Maruyama T, Takeshita K. Surgical treatment of scoliosis: a review of techniques currently applied. Scoliosis 2008;3:6.

41. Harrington PR. Treatment of scoliosis: correction and internal fixation by spine instrumentation. J Bone Joint Surg Am 1962;44:591-610.

42. Betz RR, Harms J, Clements DH 3rd, et al. Comparison of anterior and posterior instrumentation for correction of adolescent thoracic idiopathic scoliosis. Spine (Phila Pa 1976) 1999;24:225-39.

43. Betz RR, Lenke LG, Lowe GT. Proximal screw pullout during anterior instrumentation for thoracic scoliosis: preventive techniques. In: 35th Annual Meeting Scoliosis Research Society, 16-21 Oct 2000, Cairns, Austrailia. p.156.

44. Muschik MT, Kimmich H, Demmel T. Comparison of anterior and posterior double-rod instrumentation for thoracic idiopathic scoliosis: results of 141 patients. Eur Spine J 2006;15:1128-38.

45. Arlet V. Anterior thoracoscopic spine release in deformity surgery: a meta-analysis and review. Eur Spine J 2000;9 Suppl 1:S17-23.

46. Kaneda K, Shono Y, Satoh S, Abumi K. New anterior 
instrumentation for the management of thoracolumbar and lumbar scoliosis: application of the Kaneda two-rod system. Spine (Phila Pa 1976) 1996;21:125061.

47. Bridwell KH. Surgical treatment of adolescent idiopathic scoliosis: the basics and the controversies. Spine (Phila Pa 1976) 1994;19:1095-100.

48. Kim YJ, Lenke LG, Bridwell KH, Kim KL, StegerMay K. Pulmonary function in adolescent idiopathic scoliosis relative to the surgical procedure. J Bone Joint Surg Am 2005;87:1534-41.

49. Newton PO, Marks M, Faro F, et al. Use of video-assisted thoracoscopic surgery to reduce perioperative morbidity in scoliosis surgery. Spine (Phila Pa 1976) 2003;28:S249-54.

50. Luhmann SJ, Lenke LG, Kim YJ, Bridwell KH, Schootman M. Thoracic adolescent idiopathic scoliosis curves between 70 degrees and 100 degrees: is anterior release necessary? Spine (Phila Pa 1976) 2005; 30:2061-7.

51. Di Silvestre M, Bakaloudis G, Lolli F, Vommaro F, Martikos K, Parisini P. Posterior fusion only for thoracic adolescent idiopathic scoliosis of more than 80 degrees: pedicle screws versus hybrid instrumentation. Eur Spine J 2008;17:1336-49.

52. Weiss HR, Goodall D. Rate of complications in scoliosis surgery: a systematic review of the Pub Med literature. Scoliosis 2008;3:9.

53. Mueller FJ, Gluch H. Cotrel-Dubousset instrumentation for the correction of adolescent idiopathic scoliosis: long-term results with an unexpected high revision rate. Scoliosis 2012;7:13.

54. Romano M, Minozzi S, Bettany-Saltikov J, et al. Exercises for adolescent idiopathic scoliosis. Cochrane Database Syst Rev 2012;(8):CD007837.

55. Weiss HR, Reichel D, Schanz J, Zimmermann-Gudd S. Deformity related stress in adolescents with AIS. Stud Health Technol Inform 2006;123:347-51.

56. Coillard C, Leroux MA, Zabjek KF, Rivard CH. SpineCor: a non-rigid brace for the treatment of idiopathic scoliosis: post-treatment results. Eur Spine J 2003;12:141-8.

57. Negrini S, Minozzi S, Bettany-Saltikov J, et al. Braces for idiopathic scoliosis in adolescents. Cochrane Database Syst Rev 2010;(1):CD006850.

58. Coillard C, Leroux MA, Badeaux J, Rivard CH. SPINECOR: a new therapeutic approach for idio- pathic scoliosis. Stud Health Technol Inform 2002; 88:215-7.

59. Lupparelli S, Pola E, Pitta L, Mazza O, De Santis V, Aulisa L. Biomechanical factors affecting progression of structural scoliotic curves of the spine. Stud Health Technol Inform 2002;91:81-5.

60. Castro FP Jr. Adolescent idiopathic scoliosis, bracing, and the Hueter-Volkmann principle. Spine J 2003;3: 180-5.

61. Odermatt D, Mathieu PA, Beausejour M, Labelle H, Aubin CE. Electromyography of scoliotic patients treated with a brace. J Orthop Res 2003;21:931-6.

62. Weiss HR, Hawes MC. Adolescent idiopathic scoliosis, bracing and the Hueter-Volkmann principle. Spine J 2004;4:484-5.

63. Stokes IA, Burwell RG, Dangerfield PH. Biomechanical spinal growth modulation and progressive adolescent scoliosis: a test of the 'vicious cycle' pathogenetic hypothesis: summary of an electronic focus group debate of the IBSE. Scoliosis 2006;1:16.

64. Grivas TB, Vasiliadis E, Savvidou OD, Triantafyllopoulos G. What a school screening program could contribute in clinical research of idiopathic scoliosis aetiology. Disabil Rehabil 2008;30:752-62.

65. Smania N, Picelli A, Romano M, Negrini S. Neurophysiological basis of rehabilitation of adolescent idiopathic scoliosis. Disabil Rehabil 2008;30:763-71.

66. Haher T, Merola A. Atlas of spine surgical techniques. New York: Thieme; 2003.

67. Cailliet R. Scoliosis: diagnosis and management. Philadelphia: FA Davis; 1975.

68. Weiss HR, Goodall D. The treatment of adolescent idiopathic scoliosis (AIS) according to present evidence: a systematic review. Eur J Phys Rehabil Med 2008;44:177-93.

69. Weiss HR, Moramarco M, Moramarco K. Risks and long-term complications of adolescent idiopathic scoliosis surgery versus non-surgical and natural history outcomes. Hard Tissue 2013;2:27.

70. Pineda S, Bago J, Gilperez C, Climent JM. Validity of the Walter Reed Visual Assessment Scale to measure subjective perception of spine deformity in patients with idiopathic scoliosis. Scoliosis 2006;1:18.

71. Sanders JO, Harrast JJ, Kuklo TR, et al. The Spinal Appearance Questionnaire: results of reliability, validity, and responsiveness testing in patients with idiopathic scoliosis. Spine (Phila Pa 1976) 2007;32:2719- 
22.

72. Bago J, Sanchez-Raya J, Perez-Grueso FJ, Climent JM. The Trunk Appearance Perception Scale (TAPS): a new tool to evaluate subjective impression of trunk deformity in patients with idiopathic scoliosis. Scoliosis 2010;5:6.

73. Berryman F, Pynsent P, Fairbank J, Disney S. A new system for measuring three-dimensional back shape in scoliosis. Eur Spine J 2008;17:663-72.

74. Oxborrow NJ. Assessing the child with scoliosis: the role of surface topography. Arch Dis Child 2000;83: 453-5.

75. Knott P, Mardjetko S, Rollet M, et al. Evaluation of the reproducibility of the formetric $4 \mathrm{D}$ measurements for scoliosis. Scolisis 2010;5(Suppl 1):O10.

76. Asher M, Min Lai S, Burton D, Manna B. The reliability and concurrent validity of the scoliosis research society-22 patient questionnaire for idiopathic scoliosis. Spine (Phila Pa 1976) 2003;28:63-9.

77. Vasiliadis E, Grivas TB, Gkoltsiou K. Development and preliminary validation of Brace Questionnaire (BrQ): a new instrument for measuring quality of life of brace treated scoliotics. Scoliosis 2006;1:7.

78. Ward TW, Roach JW, Friel N, Kenkre TS, Brooks MM. 22r Scores in non-operated AIS patients with curves over $40^{\circ}$. In: Scoliosis Research Society 50th Annual Meeting and Course; Sep 30-Oct 3 2015; Minneapolis, MN, USA; Anniversary Abstract Booklet, Abstract 5, p. 180-1.

79. Furlan AD, Pennick V, Bombardier C, van Tulder M. 2009 updated method guidelines for systematic reviews in the Cochrane Back Review Group. Spine (Phila Pa 1976) 2009;34:1929-41.

80. Higgins JP, Green S. Cochrane handbook for systematic reviews of interventions. Version 5.1.0 [Internet]. London: The Cochrane Collaboration; 2011 [cited 2016 Aug 1]. Available from: http://www.cochranehandbook.org.

81. Downs SH, Black N. The feasibility of creating a checklist for the assessment of the methodological quality both of randomised and non-randomised studies of health care interventions. J Epidemiol Community Health 1998;52:377-84.

82. Simony A, Hansen EJ, Carreon LY, Christensen SB, Andersen MO. Health-related quality-of-life in adolescent idiopathic scoliosis patients 25 years after treatment. Scoliosis 2015;10:22.
83. Andersen MO, Christensen SB, Thomsen K. Outcome at 10 years after treatment for adolescent idiopathic scoliosis. Spine (Phila Pa 1976) 2006;31:350-4.

84. Danielsson AJ, Nachemson AL. Radiologic findings and curve progression 22 years after treatment for adolescent idiopathic scoliosis: comparison of brace and surgical treatment with matching control group of straight individuals. Spine (Phila Pa 1976) 2001;26: 516-25.

85. Danielsson AJ, Nachemson AL. Childbearing, curve progression, and sexual function in women 22 years after treatment for adolescent idiopathic scoliosis: a case-control study. Spine (Phila Pa 1976) 2001;26: 1449-56.

86. Danielsson AJ, Wiklund I, Pehrsson K, Nachemson AL. Health-related quality of life in patients with adolescent idiopathic scoliosis: a matched follow-up at least 20 years after treatment with brace or surgery. Eur Spine J 2001;10:278-88.

87. Danielsson AJ, Nachemson AL. Back pain and function 22 years after brace treatment for adolescent idiopathic scoliosis: a case-control study-part I. Spine (Phila Pa 1976) 2003;28:2078-85.

88. Danielsson AJ, Romberg K, Nachemson AL. Spinal range of motion, muscle endurance, and back pain and function at least 20 years after fusion or brace treatment for adolescent idiopathic scoliosis: a casecontrol study. Spine (Phila Pa 1976) 2006;31:275-83.

89. Pehrsson K, Danielsson A, Nachemson A. Pulmonary function in adolescent idiopathic scoliosis: a 25 year follow up after surgery or start of brace treatment. Thorax 2001;56:388-93.

90. Bunge EM, Juttmann RE, de Kleuver M, van Biezen FC, de Koning HJ. Health-related quality of life in patients with adolescent idiopathic scoliosis after treatment: short-term effects after brace or surgical treatment. Eur Spine J 2007;16:83-9.

91. Cundy TP, Antoniou G, Sutherland LM, Freeman BJ, Cundy PJ. Serum titanium, niobium, and aluminum levels after instrumented spinal arthrodesis in children. Spine (Phila Pa 1976) 2013;38:564-70.

92. Landauer F, Wimmer C, Behensky H. Estimating the final outcome of brace treatment for idiopathic thoracic scoliosis at 6-month follow-up. Pediatr Rehabil 2003;6:201-7.

93. Weiss HR, Werkmann M. Rate of surgery in a sample of patients fulfilling the SRS inclusion criteria treat- 
ed with a Cheneau brace of actual standard. Stud Health Technol Inform 2012;176:407-10.

94. De Giorgi S, Piazzolla A, Tafuri S, Borracci C, Martucci A, De Giorgi G. Cheneau brace for adolescent idiopathic scoliosis: long-term results. Can it prevent surgery? Eur Spine J 2013;22 Suppl 6:S815-22.

95. Hawes M. Impact of spine surgery on signs and symptoms of spinal deformity. Pediatr Rehabil 2006; 9:318-39.

96. Moramarco K. For adolescent idiopathic scoliosis patients, treatments should incur the least potential harm. Hard Tissue 2013;2:44.

97. Westrick ER, Ward WT. Adolescent idiopathic scoliosis: 5-year to 20-year evidence-based surgical results. J Pediatr Orthop 2011;31:S61-8.

98. Weinstein SL, Dolan LA, Spratt KF, Peterson KK, Spoonamore MJ, Ponseti IV. Health and function of patients with untreated idiopathic scoliosis: a 50year natural history study. JAMA 2003;289:559-67.

99. Weinstein SL, Dolan LA, Wright JG, Dobbs MB. Effects of bracing in adolescents with idiopathic scoliosis. N Engl J Med 2013;369:1512-21.

100. Monticone M, Ambrosini E, Cazzaniga D, Rocca B, Ferrante S. Active self-correction and task-oriented exercises reduce spinal deformity and improve quality of life in subjects with mild adolescent idiopathic scoliosis: results of a randomised controlled trial. Eur Spine J 2014;23:1204-14.

101. Wan L, Wang GX, Bian R. Exercise therapy in treatment of essential S-shaped scoliosis: evaluation of Cobb angle in breast and lumbar segment through a follow-up of half a year. Chin J Clin Rehabil 2005;9: 82-4.

102. Toledo PC, de Mello DB, Araujo ME, Daoud R, Dantas EH. Global posture reeducation effects in students with scoliosis. Fisioter Pesquisa 2011;18: 329-34.

103. Schreiber S. Schroth exercises for adolescent idiopathic scoliosis: reliability, a randomized controlled trial and clinical significance [thesis]. Edmonton: University of Alberta; 2015.

104. Schreiber S, Parent EC, Moez EK, et al. The effect of Schroth exercises added to the standard of care on the quality of life and muscle endurance in adolescents with idiopathic scoliosis-an assessor and statistician blinded randomized controlled trial: "SOSORT 2015 Award Winner”. Scoliosis 2015;10:24.

105. Kuru T, Yeldan I, Dereli EE, Ozdincler AR, Dikici F, Colak I. The efficacy of three-dimensional Schroth exercises in adolescent idiopathic scoliosis: a randomised controlled clinical trial. Clin Rehabil 2016; 30:181-90. 


\section{Appendix 1.}

\section{CBRG Trials Register, CENTRAL, MEDLINE, EMBASE and CINAHL search strategies}

\section{CBRG Trials Register}

Last searched 11 August, 2014

\#1 scoliosis

\section{CENTRAL}

Last searched 8 August, 2014

\#1 MeSH descriptor: [Scoliosis] explode all trees

\#2 scoliosis:ti,ab,kw (Word variations have been searched)

\#3 \#1 or \#2

\#4 MeSH descriptor: [Orthopedic Procedures] explode all trees \#5 MeSH descriptor: [Orthopedic Fixation Devices] explode all trees \#6 "spine fusion" or "spinal fusion" or "spinal instrumentation" or spondylodesis:ti,ab,kw (Word variations have been searched)

\#7 surg $^{\star}$ or operat ${ }^{\star}$ or realign ${ }^{\star}$ or screw* ${ }^{\star}$ or hybrid or wire* or hook or sublaminar:ti,ab,kw (Word variations have been searched)

$\# 8$ \#4 or \#5 or \#6 or \#7

\#9 MeSH descriptor: [Orthotic Devices] explode all trees

\#10 braces:ti,ab,kw (Word variations have been searched)

\#11 bracing:ti,ab,kw (Word variations have been searched)

\#12 MeSH descriptor: [Exercise] explode all trees

\#13 MeSH descriptor: [Physical Therapy Modalities] explode all trees

\#14 MeSH descriptor: [Rehabilitation] explode all trees

\#15 MeSH descriptor: [Drug Therapy] explode all trees

\#16 non-surg ${ }^{*}$ or nonsurg ${ }^{*}$ or non-operat ${ }^{*}$ or nonoperat ${ }^{*}$ or conserv $^{\star}$ or taping or tape $e^{\star}$ or immobilis* ${ }^{\star}$ or immobiliz ${ }^{\star}$ or therap ${ }^{\star}$ or electrotherap ${ }^{\star}: \mathrm{ti}, \mathrm{ab}, \mathrm{kw}$ (Word variations have been searched)

$\# 17 \# 9$ or \#10 or \#11 or \#12 or \#13 or \#14 or \#15 or \#16

\#18 \#3 and \#8 and \#17 Publication Year from 2013 to 2014, in Trials

\section{MEDLINE and MEDLINE In-Process \& Other Non-Indexed}

\section{Citations}

Last searched 8 August 2014

1. exp Spinal Diseases/

2. Scoliosis/

3. scoliosis.mp.

4. or/1-3

5. Orthopedics/

6. exp Surgical Procedures, Operative/

7. surgery.fs.

8. $\operatorname{surg} \$ . t w$.

9. operat\$.tw.

10. realign $\$ . t w$.

11. spondylodesis.tw.

12. spine fusion.tw.

13. spinal fusion.tw.

14. spinal instrumentation.tw.

15. Bone Screws/

16. screw\$.tw.

17. hybrid.tw.

18. Bone Wires/

19. sublaminar.tw.

20. wire\$.tw.
21. hook\$.tw.

22. or $/ 5-21$

23. exp Rehabilitation/

24. rehabilit\$.tw.

25. rehabilitation.fs.

26. exp Physical Therapy Modalities/

27. Physical Therapy Speciality.mp.

28. physiotherapy.tw.

29. physical therapy.tw.

30. exp Exercise/

31. exercise\$.tw.

32. Exercise Movement Techniques/

33. exp Exercise Therapy/ (30988)

34. exp Musculoskeletal Manipulations/

35. Immobilization/

36. Braces/

37. brace\$.mp.

38. bracing.mp.

39. exp Orthotic Devices/

40. Orthopedic Equipment/

41. limit 40 to $y r=" 1902-1975$ "

42. (non-surg\$ or nonsurg\$ or non-operat\$ or nonoperat\$ or conserv\$).tw.

43. (immobilis\$ or immobiliz\$ or therap\$ or taping or tape $\$$ or electrotherapy\$).tw.

44. or/23-43

45. 4 and 22 and 44

46. limit 45 to adolescent $<13$ to 18 years $>$

47. Adolescent/

48. adolescen\$.mp.

49. 47 or 48

50.45 and 49

51. 46 or 50

52. Comparative Study/

53. exp Evaluation Studies/

54. exp Follow-Up Studies/

55. exp Prospective Studies/

56. exp Cross-Over Studies/

57. exp Epidemiologic Studies/

58. exp Case-Control Studies/

59. exp Cohort Studies/

60. exp Cross-Sectional Studies/

61. (cohort adj (study or studies)).mp.

62. cohort analy\$.mp.

63. (follow up adj (study or studies)).mp.

64. (observational adj (study or studies)).mp.

65. longitudinal.mp.

66. retrospective.mp.

67. cross sectional.mp.

68. control\$.mp.

69. prospective\$.mp.

70. volunteer.mp.

71. or $/ 52-70$

72. randomized controlled trial.pt.

73. controlled clinical trial.pt.

74. randomi\#ed.ti,ab. 
75. placebo.ti,ab.

76. drug therapy.fs.

77. randomly.ti,ab.

78. trial.ti,ab.

79. groups.ti,ab.

80. or/72-79

81. (Animals not (Humans and Animals)).sh.

82. 80 not 81

83.71 not 81

84.82 or 83

85.51 and 84

86. limit 85 to $y r=2013-2014$

87. limit 85 to ed $=20130705-20140808$

88.86 or 87

\section{EMBASE}

Last searched 8 August 2014

1. exp spine/

2. exp spine disease/

3. exp scoliosis/

4. exp idiopathic scoliosis/

5. scoliosis.mp.

6. or/1-5

7. orthopedics/

8. exp surgery/

9. su.fs.

10. surg\$.ti,ab.

11. operat\$.ti,ab.

12. realign $\$ . t i, a b$.

13. spondylodesis.ti,ab.

14. spine fusion.ti,ab.

15. spinal fusion.ti,ab.

16. spinal instrumentation.ti,ab.

17. bone screw/

18. screw\$.ti,ab.

19. hybrid.ti,ab.

20. Kirschner wire/

21. sublaminar.ti,ab.

22. wire\$.ti,ab.

23. hook\$.ti,ab.

24. or/7-23

25. exp rehabilitation/

26. rehabilitat\$.ti,ab.

27. rh.fs.

28. exp physiotherapy/

29. physiotherapist/

30. physiotherapy.ti,ab.

31. physical therapy.ti,ab.

32. exp exercise/

33. exercise\$.ti,ab.

34. kinesiotherapy/

35. exp manipulative medicine/

36. immobilization/

37. brace/

38. brace \$.mp.

39. bracing.mp.

40. exp orthotics/

41. exp orthopedic equipment/

42. (non-surg\$ or nonsurg\$ or non-operat\$ or nonoperat\$ or con- serv\$).ti,ab.

43. (immobilis\$ or immobiliz\$ or therap\$ or taping or tape $\$$ or electrotherap\$).ti,ab.

44. or/25-43

45. 6 and 24 and 44

46. limit 45 to adolescent $<13$ to 17 years $>$

47. adolescent/

48. adolescen\$.mp.

49. or/47-48

50. 45 and 49

51. 46 or 50

52. exp Clinical Study/

53. exp Case Control Study/

54. exp Family Study/

55. exp Longitudinal Study/

56. exp Retrospective Study/

57. exp Prospective Study/

58. exp Cohort Analysis/

59. (cohort adj (study or studies)).mp.

60. (case control adj (study or studies)).mp.

61. (follow up adj (study or studies)).mp.

62. (observational adj (study or studies)).mp.

63. (epidemiologic\$ adj (study or studies)).mp.

64. (cross sectional adj (study or studies)).mp.

65. exp Comparative Study/

66. evaluation study.mp.

67. follow-up study.mp. or exp Follow Up/

68. Crossover Procedure/

69. prospective\$.mp.

70. $\exp$ VOLUNTEER/

71. or $/ 52-70$

72. Clinical Article/

73. exp Clinical Study/

74. Clinical Trial/

75. Controlled Study/

76. Randomized Controlled Trial/

77. Major Clinical Study/

78. Double Blind Procedure/

79. Multicenter Study/

80. Single Blind Procedure/

81. Phase 3 Clinical Trial/

82. Phase 4 Clinical Trial/

83. crossover procedure/

84. placebo/

85. or/72-84

86. allocat\$.mp.

87. assign $\$ . m p$.

88. blind\$.mp.

89. (clinic\$ adj25 (study or trial)).mp.

90. compar\$.mp.

91. control\$.mp.

92. cross?over.mp.

93. factorial\$.mp.

94. follow?up.mp.

95. placebo\$.mp.

96. prospectiv\$.mp.

97. random\$.mp.

98. ((singl\$ or doubl\$ or trebl\$ or tripl\$) adj25 (blind\$ or mask\$)).

$\mathrm{mp}$. 
99. trial.mp.

100. (versus or vs).mp.

101. or/86-100

102. 85 or 101

103. exp animals/ or exp invertebrate/ or animal experiment/ or animal model/ or animal tissue/ or animal cell/ or nonhuman/

104. human/ or normal human/ or human cell/

105. 103 and 104

106. 103 not 105

107. 102 not 106

108. 71 not 106

109. 107 or 108

110. 51 and 109

111. limit 110 to $\mathrm{yr}=2013-2014$

112. limit 110 to $\mathrm{em}=201326-201431$

113. 111 or 112

\section{CINAHL}

Last searched 8 August 2014

v S85 S83 or S84

S84 S82 and EM 20130705-20140808

S83 S82 Limiters - Published Date: 20130701-20140831

S82 S77 OR S81

S81 S76 AND S80

S80 S78 OR S79

S79 adolescen*

S78 MH Adolescence+

S77 S34 AND S39 AND S75 Limiters - Age Groups: Adolescent: 1318 years

\section{S76 S34 AND S39 AND S75}

S75 S56 OR S74

S74 S57 or S58 or S59 or S60 or S61 or S62 or S63 or S64 or S65 or S66 or S67 or S68 or S69 or S70 or S71 or S72 or S73

S73 TI (immobilis ${ }^{\star}$ or immobiliz ${ }^{*}$ or therap* or taping or tape* or electrotherap ${ }^{\star}$ ) or AB (immobilis ${ }^{\star}$ or immobiliz ${ }^{\star}$ or therap ${ }^{\star}$ or taping or tape $\mathrm{e}^{\star}$ or electrotherap $\left.{ }^{\star}\right)$

S72 TI (non-surg* ${ }^{\star}$ or nonsurg* ${ }^{*}$ or non-operat ${ }^{*}$ or nonoperat ${ }^{\star}$ or conserv $^{\star}$ ) or $\mathrm{AB}$ (non-surg ${ }^{\star}$ or nonsurg ${ }^{\star}$ or non-operat ${ }^{\star}$ or nonoperat $^{*}$ or conserv $\left.{ }^{*}\right)$

S71 MH "Orthopedic Equipment and Supplies+"

S70 orthotic ${ }^{\star}$

S69 (MH "Orthoses+") OR "orthoses"

S68 bracing

S67 brace*

S66 MH Immobilization

S65 MH Manipulation, Orthopedic

S64 MH Therapeutic Exercise+

S63 TI exercise* or AB exercise*

S62 MH Exercise+

S61 TI "physical therapy" or AB "physical therapy"

S60 TI physiotherapy or $A B$ physiotherapy

S59 MH Physical Therapists

S58 MH Physical Therapy+

S57 MH Rehabilitation+

S56 (TI hook* or AB hook ${ }^{\star}$ ) AND (S40 OR S41 OR S42 OR S43 OR S44 OR S45 OR S46 OR S47 OR S48 OR S49 OR S50 OR S51 OR S52 OR S53 OR S54 OR S55)
S55 TI hook* or AB hook ${ }^{\star}$

S54 TI wire ${ }^{\star}$ or $\mathrm{AB}$ wire

S53 TI sublaminar or $\mathrm{AB}$ sublaminar

S52 TI hybrid or $\mathrm{AB}$ hybrid

S51 TI screw* ${ }^{*}$ or AB screw*

S50 MH Orthopedic Fixation Devices

S49 TI "spinal instrumentation" or AB "spinal instrumentation"

S48 TI "spinal fusion" or AB "spinal fusion"

S47 TI "spine fusion" or AB "spine fusion"

S46 TI spondylodesis or $\mathrm{AB}$ spondylodesis

S45 TI realign* or AB realign*

S44 TI operat* ${ }^{*}$ or AB operat ${ }^{*}$

S43 TI surg* or AB surg*

S42 MW Surgery

S41 MH Surgery, Operative+

S40 MH Orthopedics

S39 S35 OR S36 OR S37 OR S38

S38 scoliosis

S37 MH Scoliosis+

S36 MH Spinal Diseases+

S35 MH Spine+

S34 S32 or S33

S33 S30 not S31

S32 S14 not S31

S31 MH Animals

S30 S15 OR S16 OR S17 OR S18 OR S19 OR S 20 OR S 21 OR S22

OR S 23 OR S 24 OR S 25 OR S26 OR S 27 OR S 28 OR S 29

S29 volunteer*

S28 prospective*

S27 control*

S26 retrospective

S25 longitudinal

S24 "observational studies" or "observational study"

S23 "follow-up stud*" or "followup stud*"

S22 "cohort analys"”

S21 "cohort studies" or "cohort study"

S20 MH Epidemiological Research+

S19 MH Prospective Studies+

S18 MH Evaluation Research+

S17 MH Comparative Studies

S16 latin square

S15 MH Study Design+

S14 S1 OR S2 OR S3 OR S4 OR S5 OR S6 OR S7 OR S8 OR S9 OR S10 OR S11 OR S12 OR S13

S13 MH Random Sample

S12 random*

S11 MW Drug Therapy

S10 placebo $^{*}$

S9 MH Placebos

S8 MH Placebo Effect

$\mathrm{S} 7 \mathrm{TI}$ groups or $\mathrm{AB}$ groups

S6 triple-blind

S5 single-blind

S4 double-blind

S3 clinical W3 trial

S2 "randomi?ed controlled trial*"

S1 (MH "Clinical Trials+") 


\section{Appendix 2.}

\section{OTHER SEARCH STRATEGIES}

\section{PsycINFO}

Last searched 8 August 2014

1 scoliosis.mp.

$2{\text { ( } \operatorname{surg}^{\star} \text { or operat }}^{\star}$ or realign ${ }^{\star}$ or spondylodesis or fusion or instrumentation or screw ${ }^{\star}$ or hook ${ }^{\star}$ or hybrid or wire ${ }^{\star}$ or sublaminar).mp. [mp=title, abstract, heading word, table of contents, key concepts, original title, tests \& measures]

3 (rehabilit $^{\star}$ or therap ${ }^{\star}$ or physiotherapy or exercise* or braces or bracing or orthotic ${ }^{\star}$ or non-surg* or nonsurg $^{\star}$ or non-operat ${ }^{\star}$ or nonoperat ${ }^{\star}$ or conserv $v^{\star}$ or immobilis ${ }^{\star}$ or immobiliz ${ }^{\star}$ or taping or tape $e^{\star}$ or electrotherapy).mp. [mp=title, abstract, heading word, table of contents, key concepts, original title, tests \& measures]

41 and 2 and 3

5 limit 4 to $y r=2013-2014$

\section{PEDro}

Last searched 8 August 2014

Abstract \& Title: scoliosis

AND

Method: clinical trial

New records added since 05/07/2013

\section{PubMed}

Searched 11 August 2014. This search was designed to capture citations not indexed in MEDLINE

(surg $^{\star}$ or fus ${ }^{\star}$ or orthopedic ${ }^{\star}$ or instrument ${ }^{\star}$ or screw ${ }^{\star}$ or wire ${ }^{\star}$ or hook ${ }^{*}$ [Title/Abstract]) OR (nonsurg* or non-surg or nonop ${ }^{*}$ or non-op ${ }^{\star}$ or immobiliz ${ }^{\star}$ or immobilis ${ }^{\star}$ or exercise ${ }^{\star}$ or therap ${ }^{\star}$ or braces or bracing or taping or tape $e^{\star}$ or electrotherap ${ }^{\star}$ or rehab $^{\star}$ or conserv ${ }^{\star}\left[\right.$ Title/Abstract] AND (adolescen ${ }^{\star}$ AND scoliosis[Title/Abstract] AND (“2013/07/05”[Date - Publication] : “3000”[Date - Publication] NOT MEDLINE[sb]

\section{UKCTG}

Last searched August 2014

scoliosis

\section{ClinicalTrials.gov}

Last searched 8 August 2014

Condition: scoliosis

\section{WHO ICTRP}

Last searched 8 August 2014

Condition: scoliosis

\section{EThOS}

Last searched August 2014

Scoliosis 


\section{Appendix 3.}

\section{Criteria for assessing risk of bias for internal validity for randomised and non- randomised studies (Downs and Black 1998; Furlan 2009)}

Risk of bias is low if compliance with the interventions was acceptable on the basis of reported intensity/dosage, duration, number, and frequency for both index and control intervention(s). For singlesession interventions (for example surgery), this item is irrelevant.

\section{Co-interventions}

Risk of bias is low if no co-interventions were provided, or if they were similar between index and control groups.

Attrition bias

\section{Incomplete outcome data}

Risk of attrition bias is low if no outcome data were missing; reasons for missing outcome data were unlikely to be related to the true outcome (for survival data, censoring unlikely to be introducing bias); missing outcome data were balanced in numbers, with similar reasons for missing data across groups; for dichotomous outcome data, the proportion of missing outcomes compared with the observed event risk was not enough to have a clinically relevant impact on the intervention effect estimate; for continuous outcome data, the plausible effect size (difference in means or standardised difference in means) among missing outcomes was not enough to have a clinically relevant impact on observed effect size, or missing data were imputed using appropriate methods (if dropouts were very large, imputation using even 'acceptable' methods may still suggest a high risk of bias). The percentage of withdrawals and dropouts should not exceed 20\% for short-term follow-up and 30\% for long-term follow-up and should not lead to substantial bias (these percentages are commonly used but are arbitrary and are not supported by the literature).

\section{Intention-to-treat analysis}

Risk of bias is low if all randomly assigned participants were reported/analysed in the group to which they were allocated by randomisation.

\section{Measurement/detection}

\section{Blinding of outcome assessment}

Risk of detection bias is low if blinding of the outcome assessment was ensured and it was unlikely that the blinding could have been broken; or if no blinding or incomplete blinding was performed, but the review authors judge that the outcome was not likely to be influenced by lack of blinding, or for participant-reported outcomes in which the participant was the outcome assessor (e.g. pain, disability): Risk of bias for outcome assessors is low if risk of bias for participant blinding is low;for outcome criteria that are clinical or therapeutic events that will be determined by the interaction between participants and care providers (e.g. co-interventions, length of hospitalisation, treatment failure), in which the care provider is the outcome assessor: Risk of bias for outcome assessors is low if risk of bias for care providers is low; andfor outcome criteria that are assessed from data from medical forms: Risk of bias is low if the treatment or adverse effects of the treatment could not be noticed in the extracted data.

\section{Timing of outcome assessments}

Risk of bias is low if all important outcome assessments for all intervention groups were measured at the same time, or if analyses adjust for different lengths of follow-up.

\section{Selective reporting}

\section{Data dredging}

Risk of bias is low if all analyses were planned at the outset of the study.

Risk of bias is high if analyses were conducted retrospectively (for example retrospective unplanned subgroup analyses).

\section{Outcome measures}

Risk of reporting bias is low if the study protocol is available and all of the study's pre specified (primary and secondary) outcomes that are of interest in the review have been reported in the pre-specified way, or if the study protocol is not available, but it is clear that the published reports include all expected outcomes, including those that were pre-specified (convincing text of this nature may be uncommon).

Risk of reporting bias is high if not all of the study's pre-specified primary outcomes have been reported; one or more primary outcomes were reported using measurements, analysis methods, or subsets of the data (for example sub-scales) that were not prespecified; one or more reported primary outcomes were not pre-specified (unless clear justification for their reporting was provided, such as an unexpected adverse effect); one or more outcomes of interest in the review were reported incompletely, so that they cannot be entered into a metaanalysis; the study report failed to include results for a key outcome that would be expected to have been reported for such a study.

${ }^{*}$ Items are relevant only to non-randomised studies.

\section{Questions for assessing clinical relevance}

1. Are the participants described in detail so that you can decide whether they are comparable with those that you see in your practice?Yes/No/Unsure 2. Are the interventions and treatment settings described well enough so that you can provide the same for your patients?Yes/No/Unsure 3. Were all clinically relevant outcomes measured and reported?Yes/No/Unsure 4 . Is the size of the effect clinically important?Yes/No/Unsure 5. Are the likely treatment benefits worth the potential harms?Yes/No/Unsure 